\title{
Serum Sodium Modifies the Association of Systolic Blood Pressure with Mortality in Peritoneal Dialysis Patients
}

\author{
Yagui Qiu ${ }^{a}$ Hongjian Ye ${ }^{a}$ Li Fan $^{a}$ Xunhua Zheng ${ }^{a}$ Wei Li ${ }^{a}$ b \\ Fengxian Huang $^{\mathrm{a}}$ Wei Chen $^{\mathrm{a}}$ Xiao Yang $^{\mathrm{a}}$ Haiping Mao ${ }^{\mathrm{a}}$ \\ aDepartment of Nephrology, The First Affiliated Hospital of Sun Yat-sen University, NHC \\ Key Laboratory of Nephrology, Guangdong Provincial Key Laboratory of Nephrology, \\ Guangzhou, China; bepartment of Nephrology, The First People's Hospital of Foshan, \\ Foshan, China
}

\section{Keywords}

Serum sodium · Systolic blood pressure $\cdot$ Peritoneal dialysis · Mortality

\begin{abstract}
Introduction: High serum sodium is associated with increased blood pressure (BP) in dialysis patients, which is a risk factor for cardiovascular (CV) disease. However, the interaction between serum sodium and BP and their association with clinical outcomes in peritoneal dialysis (PD) patients is uncertain. Methods: We analyzed a retrospective cohort of 1,656 incident PD patients from January 2006 to December 2013, who were followed up until December 2018. Cox proportional hazards regression models were used to evaluate the association of serum sodium and BP with all-cause and CV mortality. A priori interaction between serum sodium and systolic BP (SBP) was explored, and a subgroup analysis was performed by stratifying SBP into the following 3 groups: <110, 110-130, and $>130 \mathrm{~mm}$ Hg. Results: Mean baseline serum sodium was $140.2 \pm 3.6 \mathrm{mmol} / \mathrm{L}$, mean SBP was $137 \pm 20 \mathrm{~mm} \mathrm{Hg}$, and diastolic BP was $85 \pm$ $14 \mathrm{~mm} \mathrm{Hg}$. During a median (range) follow-up time of 46.5 (2.6-154.3) months, 507 patients died, 252 of whom died due to CV disease. SBP did not predict all-cause and CV mortality when BP was assessed as a continuous variable. However, SBP $>130$ or $<110 \mathrm{~mm} \mathrm{Hg}$ was associated with higher risk of all-cause and CV mortality compared with SBP of $110-130 \mathrm{~mm} \mathrm{Hg}$. There was a significant interaction between baseline serum sodium and SBP for all-cause mortality ( $p$ for interaction $=0.016$ ). In subgroup analysis, among those with SBP $>130 \mathrm{~mm}$ $\mathrm{Hg}$, the risk of all-cause mortality was elevated in those with serum sodium $\geq 140 \mathrm{mmol} / \mathrm{L} \mathrm{(ad}$ justed hazard ratio [aHR] 1.45 [95\% confidence interval (CI): 1.07-1.98]), but not for those with serum sodium <140 mmol/L (aHR 1.27 [95\% Cl: 0.89-1.82]). Conversely, among those with SBP
\end{abstract}

Yagui Qiu and Hongjian Ye contributed equally to this work. 
$<110 \mathrm{~mm} \mathrm{Hg}$, those with serum sodium $<140 \mathrm{mmol} / \mathrm{L}$ had an elevated risk of mortality (aHR 1.99 [95\% Cl: 1.31-3.02]), but not those with serum sodium $\geq 140 \mathrm{mmol} / \mathrm{L}$ (aHR 1.15 [95\% Cl: $0.74-1.79])(p$ for interaction $=0.028)$. Conclusion: The association of BP with mortality was modified by serum sodium levels in PD patients. Further studies are needed to evaluate whether individualized BP control based on serum sodium levels contributes to improve patient outcomes.

(C) 2020 The Author(s).

Published by S. Karger AG, Basel

\section{Introduction}

Abnormal sodium levels may be associated with adverse outcomes in dialysis patients [1, 2]. A U-shaped relationship between serum sodium levels and mortality has been observed in non-dialysis CKD patients and hemodialysis (HD) patients, among whom both low and high levels of serum sodium are associated with an increased risk of mortality [3, 4]. Similarly, in peritoneal dialysis (PD) patients, our recent study and others have demonstrated that hyponatremia predicts a higher risk of infection-related and all-cause death $[5,6]$.

Blood pressure (BP) has been reported to be an independent predictor of mortality [7-10]. Associations between serum sodium concentration and BP have been observed both in the general population and dialysis patients. In a cohort study of 3,603 people from the general population, a higher serum sodium concentration was independently associated with an increased BP [11]. In addition, enhancing peritoneal sodium removal using low-sodium dialysate has advantages for hypertensive PD patients $[12,13]$. Despite the close relationship between serum sodium and BP that has been identified, few studies have been performed to address the interaction effects between serum sodium concentration and BP on mortality in PD patients.

Therefore, in this retrospective cohort study, we evaluated the association of baseline BP with all-cause and cardiovascular (CV) mortality in PD patients. We then explored a priori interaction between BP, serum sodium, and mortality.

\section{Materials and Methods}

\section{Participants}

From January 1, 2006, to December 31, 2013, 1,884 participants were consecutively recruited from our center. Eligible participants were over 18 years of age and undergoing continuous ambulatory peritoneal dialysis (CAPD) treatment for $>3$ months. We excluded those with a history of kidney transplantation $(n=16)$, HD longer than 3 months $(n=73)$, malignant disease $(n=30)$, or missing serum sodium or BP data at baseline $(n=2)$. There were 1,656 participants included in the final analysis.

\section{Demographic and Clinical Data}

Participants' demographic, biochemical, and clinical data were collected at the time of study enrollment. Demographic and clinical characteristics were obtained from participant's medical record. Demographic data included age, gender, primary cause of ESRD, and comorbidities (CV diseases [CVDs] and diabetes). The presence of CVDs was defined as congestive heart failure, ischemic heart disease, cerebrovascular disease, and peripheral vascular disease [14]. Biochemical variables, including hemoglobin, serum sodium, albumin, total cholesterol, triglyceride, high-density lipoprotein cholesterol, low-density lipoprotein cholesterol, calcium, phosphate, and intact parathyroid hormone, were measured at the clinical laboratory of the First Affiliated Hospital of Sun Yat-sen University within 3 months of PD initi- 
ation. Residual renal function was determined by residual glomerular filtration rate (rGFR) derived from the average of 24-h urinary urea and $\mathrm{Cr}$ clearance normalized to a standard body surface area of $1.73 \mathrm{~m}^{2}$. Total $\mathrm{Cr}$ clearance and total $\mathrm{Kt} / V_{\text {urea }}$ were calculated using PD Adequest software (Baxter Healthcare Corporation, Chicago, IL, USA). BP was measured twice at the baseline visit, and the mean of 2 measurements was used.

Outcomes

The primary outcome was all-cause mortality and the secondary outcome was CV mortality. CV mortality was defined as death due to myocardial infarction, congestive heart failure, arrhythmia, cerebrovascular accident, peripheral vascular disease, and sudden death. Sudden death was diagnosed as unexpected natural death that occurred within $1 \mathrm{~h}$ of symptom onset and without any previous condition that would appear fatal. We defined survival time for each participant as the time from enrollment to death or administrative censoring (i.e., transfer to HD, kidney transplantation, transfer to another dialysis center, loss to follow-up, or end of the study period on December 31,2018).

\section{Statistical Analysis}

Results were presented as the mean \pm standard deviation or median $(25$ th, 75 th percentile) for continuous variables, as appropriate, as well as number (percent) for categorical variables. Participants were stratified by baseline serum sodium with a threshold of $140 \mathrm{mmol} / \mathrm{L}$, and baseline demographic and laboratory variables were compared between 2 groups using a 2-sample $t$ test or Mann-Whitney $\mathrm{U}$ test for continuous variables and a $\chi^{2}$ test for categorical variables, as appropriate.

Unadjusted and adjusted Cox proportional hazards regression models were used to evaluate the associations of SBP with all-cause and CV mortality. The following potential confounding covariates were included in the adjusted model: age, gender, history of CV disease (CVD), diabetic status, hemoglobin, serum albumin, 24-h urine volume, and antihypertensive medications. Curve fitting was further conducted with a fractional polynomial model to evaluate the possibility of a nonlinear association between continuous SBP levels and outcomes, which was predicted from Cox models after adjusting for the confounding factors described above. The interaction of serum sodium with the association between SBP and all-cause and CV mortality was also evaluated using the Cox regression model, with adjustments for potential confounders. Based on these results, we further investigated the relationship between SBP and outcomes by stratifying SBP into the following 3 groups: $<110$, 110-130, and $>130 \mathrm{~mm} \mathrm{Hg}$. All analyses were performed using SPSS statistical software (version 19.0; IBM, Armonk, NY, USA) or Stata software (version 15.1; Stata Corp, College Station, TX, USA), as appropriate. A $p$ value $<0.05$ was considered to be statistically significant.

\section{Results}

\section{Participant Baseline Characteristics}

Table 1 summarizes the baseline characteristics of participants stratified by serum sodium levels. The mean age of participants was $47.5 \pm 15.3$ years, and $59.8 \%$ were male. The leading cause of ESRD in the cohort was glomerulonephritis, with a prevalence of $61.1 \%$. Thirty-seven percent of participants had a history of CVD and $25.5 \%$ had diabetes. The mean SBP was $137 \pm 20 \mathrm{~mm} \mathrm{Hg}$ and diastolic BP (DBP) was $85 \pm 14 \mathrm{~mm} \mathrm{Hg}$. The mean serum sodium was $140.2 \pm 3.6 \mathrm{mmol} / \mathrm{L}$. Compared with participants with baseline serum sodium $<140$ $\mathrm{mmol} / \mathrm{L}$, those with baseline serum sodium $\geq 140 \mathrm{mmol} / \mathrm{L}$ were more likely to be male and had a higher BMI, SBP and DBP, hemoglobin, serum albumin, rGFR, 24-h urine volume, and 
Table 1. Baseline characteristics by baseline serum sodium

\begin{tabular}{|c|c|c|c|c|}
\hline Variables & $\begin{array}{l}\text { Overall } \\
(n=1,656)\end{array}$ & $\begin{array}{l}\mathrm{Na}<140 \mathrm{mmol} / \mathrm{L} \\
(n=636)\end{array}$ & $\begin{array}{l}\mathrm{Na} \geq 140 \mathrm{mmol} / \mathrm{L} \\
(n=1,020)\end{array}$ & $p$ value \\
\hline Serum sodium, mmol/L & $140.2 \pm 3.6$ & $136.7 \pm 2.6$ & $142.3 \pm 2.1$ & NA \\
\hline Age, years & $47.5 \pm 15.3$ & $47.7 \pm 15.6$ & $47.3 \pm 15.1$ & 0.595 \\
\hline Male, \% & $990(59.8)$ & $349(54.9)$ & $641(62.8)$ & 0.001 \\
\hline Cause of ESRD, $n(\%)$ & & & & 0.057 \\
\hline Glomerulonephritis & $1,012(61.1)$ & $374(58.8)$ & $638(62.5)$ & \\
\hline Diabetic kidney disease & $377(22.8)$ & $166(26.1)$ & $221(20.7)$ & \\
\hline Hypertension & $119(7.2)$ & $39(6.1)$ & $80(7.8)$ & \\
\hline Others & $148(8.9)$ & $57(9.0)$ & $91(8.9)$ & \\
\hline History of CVD, $n(\%)$ & $612(37.0)$ & $225(35.4)$ & $387(37.9)$ & 0.318 \\
\hline Diabetes, $n(\%)$ & $423(25.5)$ & $184(28.9)$ & $239(23.4)$ & 0.015 \\
\hline $\mathrm{BMI}, \mathrm{kg} / \mathrm{m}^{2}$ & $21.6 \pm 3.2$ & $21.2 \pm 3.0$ & $21.9 \pm 3.2$ & $<0.001$ \\
\hline $\mathrm{SBP}, \mathrm{mm} \mathrm{Hg}$ & $137 \pm 20$ & $134 \pm 20$ & $138 \pm 19$ & $<0.001$ \\
\hline $\mathrm{DBP}, \mathrm{mm} \mathrm{Hg}$ & $85 \pm 14$ & $83 \pm 15$ & $86 \pm 14$ & $<0.001$ \\
\hline Hemoglobin, g/dL & $105.5 \pm 21.8$ & $102.6 \pm 22.7$ & $107.3 \pm 21.1$ & $<0.001$ \\
\hline Serum albumin, g/L & $37.3 \pm 5.2$ & $36.1 \pm 5.4$ & $38.0 \pm 4.9$ & $<0.001$ \\
\hline Total cholesterol, mmol/L & $5.10 \pm 1.34$ & $5.12 \pm 1.41$ & $5.08 \pm 1.29$ & 0.571 \\
\hline Triglycerides, mmol/L & $1.42(1.01-2.02)$ & $1.39(0.97-1.96)$ & $1.44(1.03-2.07)$ & 0.220 \\
\hline HDL cholesterol, mmol/L & $1.24 \pm 0.39$ & $1.24 \pm 0.49$ & $1.23 \pm 0.38$ & 0.534 \\
\hline LDL cholesterol, mmol/L & $2.94 \pm 1.01$ & $2.93 \pm 1.06$ & $2.94 \pm 0.98$ & 0.883 \\
\hline Serum calcium, mmol/L & $2.26 \pm 0.23$ & $2.25 \pm 0.24$ & $2.27 \pm 0.22$ & 0.155 \\
\hline Serum phosphate, mmol/L & $1.44 \pm 0.43$ & $1.48 \pm 0.45$ & $1.42 \pm 0.42$ & 0.013 \\
\hline $\mathrm{iPTH}, \mathrm{pg} / \mathrm{mL}$ & $227(107-412)$ & $221(96-414)$ & $229(113-411)$ & 0.476 \\
\hline $\mathrm{rGFR}, \mathrm{mL} / \mathrm{min} / 1.73 \mathrm{~m}^{2}$ & $3.26(1.88-5.09)$ & $2.83(1.51-4.55)$ & $3.53(2.16-5.46)$ & $<0.001$ \\
\hline 24-h urine volume, mL & $800(500-1,200)$ & $700(400-1,100)$ & $800(500-1,200)$ & $<0.001$ \\
\hline Total CCL, L/week per $1.73 \mathrm{~m}^{2}$ & $86.78 \pm 29.06$ & $83.66 \pm 27.65$ & $88.67 \pm 29.73$ & 0.002 \\
\hline Total Kt/Vurea & $2.47 \pm 0.68$ & $2.47 \pm 0.68$ & $2.47 \pm 0.68$ & 0.856 \\
\hline ACEi/ARB use & $221(49.3)$ & $319(50.2)$ & $546(53.5)$ & 0.199 \\
\hline
\end{tabular}

Data presented as mean \pm SD, $n$ (percentage), or median (25th, 75th). Bold values indicate $p$ values less than 0.05 . DBP, diastolic blood pressure; SBP; systolic blood pressure; CVD, cardiovascular disease; HDL, high-density lipoprotein; LDL, low-density lipoprotein; iPTH, intact parathyroid hormone; rGFR, residual glomerular filtration rate; CCL, Cr clearance; Kt/ Vurea, urea clearance (Kt) normalized to total body water (V); ACEi, angiotensin-converting enzyme inhibitors; ARB, angiotensin II receptor blockers; SD, standard deviation.

total $\mathrm{Cr}$ clearance. However, fewer of these patients had a history of diabetes, and serum phosphorus levels were lower.

\section{Factors Associated with SBP}

Table 2 shows the regression coefficients of various factors that were associated with SBP levels using multivariate linear regression. After adjusting for sex, age, diabetes, history of CVD, serum albumin, hemoglobin, 24-h urine volume, and BMI, we found that serum sodium $(\beta=0.626, p<0.001), 24$-h urine volume $(\beta=0.003, p=0.001)$, and BMI $(\beta=0.478, p=0.004)$ were positively associated with SBP, while female sex $(\beta=-3.031, p=0.004)$, serum albumin $(\beta=-0.375, p=0.001)$, and hemoglobin $(\beta=-0.089, p<0.001)$ were negatively related to SBP.

\section{Baseline SBP, Serum Sodium, and Mortality}

Over a median follow-up of 46.5 (2.6-154.3) months, 507 participants (30.6\%) died, of whom 252 (49.7\%) died as a result of CVD. In our study, both all-cause and CV mortality rates among participants with a serum sodium $<140 \mathrm{mmol} / \mathrm{L}$ were significantly higher than those with a serum sodium $\geq 140 \mathrm{mmol} / \mathrm{L}\{82.5$ vs. 65.3 events per 1,000 patient-years (HR $1.29,95 \%$ 
Table 2. Factors associated with SBP

\begin{tabular}{|c|c|c|c|c|c|}
\hline \multirow[t]{2}{*}{ Variables } & \multicolumn{2}{|c|}{ Unstandardized coefficients } & \multirow{2}{*}{$\begin{array}{l}\text { Standardized } \\
\text { coefficients }\end{array}$} & \multirow[t]{2}{*}{$T$} & \multirow[t]{2}{*}{$p$ value } \\
\hline & $B$ & standard error & & & \\
\hline Sex (female) & -3.031 & 1.038 & -0.075 & -2.921 & 0.004 \\
\hline Age, year & -0.041 & 0.038 & -0.031 & -1.080 & 0.280 \\
\hline Diabetes (yes/no) & 2.288 & 1.370 & 0.048 & 1.670 & 0.095 \\
\hline History of CVD (yes/no) & 1.871 & 1.047 & 0.046 & 1.788 & 0.074 \\
\hline Serum albumin, $\mathrm{g} / \mathrm{L}$ & -0.375 & 0.114 & -0.096 & -3.282 & 0.001 \\
\hline Serum sodium, mmol/L & 0.626 & 0.142 & 0.112 & 4.407 & $<0.001$ \\
\hline $\mathrm{HGB}, \mathrm{g} / \mathrm{L}$ & -0.089 & 0.025 & -0.096 & -3.605 & $<0.001$ \\
\hline 24-h Urine volume, mL/day & 0.003 & 0.001 & 0.090 & 3.479 & 0.001 \\
\hline $\mathrm{BMI}, \mathrm{kg} / \mathrm{m}^{2}$ & 0.478 & 0.167 & 0.076 & 2.867 & 0.004 \\
\hline
\end{tabular}

$F=11.50, p<0.001 . R^{2}=0.063$. Bold values indicate $p$ values less than 0.05 . Analysis of factors associated with SBP by multivariable linear regression. SBP, systolic blood pressure; HGB, hemoglobin; CVD, cardiovascular disease.

Table 3. Association of baseline BP with all-cause and CV mortality by baseline serum sodium levels

\begin{tabular}{|c|c|c|c|c|c|c|c|c|}
\hline & \multicolumn{4}{|l|}{ All-cause mortality } & \multicolumn{4}{|l|}{ CV mortality } \\
\hline & \multicolumn{2}{|l|}{ unadjusted model } & \multicolumn{2}{|l|}{ multivariate model } & \multicolumn{2}{|l|}{ unadjusted model } & \multicolumn{2}{|l|}{ multivariate model } \\
\hline & $\operatorname{HR}(95 \% \mathrm{CI})$ & $p$ value & $\operatorname{HR}(95 \% \mathrm{CI})$ & $p$ value & $\operatorname{HR}(95 \% \mathrm{CI})$ & $p$ value & $\operatorname{HR}(95 \% \mathrm{CI})$ & $p$ value \\
\hline \multicolumn{9}{|c|}{ Interaction analysis for mortality in the overall cohort ${ }^{\mathrm{b}}$} \\
\hline \multicolumn{9}{|c|}{ SBP/DBP ( $5 \mathrm{~mm}$ Hg increase) $\times$ sodium group } \\
\hline $\mathrm{SBP} \times$ sodium group & \multicolumn{2}{|l|}{$p_{\text {for interaction }}=\mathbf{0 . 0 0 7}$} & \multicolumn{2}{|l|}{$p_{\text {for interaction }}=\mathbf{0 . 0 1 6}$} & \multicolumn{2}{|l|}{$p_{\text {for interaction }}=0.079$} & \multicolumn{2}{|l|}{$p_{\text {for interaction }}=0.203$} \\
\hline $\mathrm{DBP} \times$ sodium group & \multicolumn{2}{|c|}{$p_{\text {for interaction }}=\mathbf{0 . 0 2 4}$} & \multicolumn{2}{|l|}{$p_{\text {for interaction }}=\mathbf{0 . 0 3 0}$} & \multicolumn{2}{|l|}{$p_{\text {for interaction }}=\mathbf{0 . 0 2 1}$} & \multicolumn{2}{|l|}{$p_{\text {for interaction }}=0.058$} \\
\hline \multicolumn{9}{|l|}{ Overall cohort $(n=1,656)^{\mathrm{a}}$} \\
\hline SBP, $5 \mathrm{~mm} \mathrm{Hg}$ increase & $1.03(1.01-1.05)$ & 0.018 & $1.01(0.99-1.03)$ & 0.126 & $1.03(1.00-1.06)$ & 0.049 & $1.01(0.98-1.04)$ & 0.394 \\
\hline DBP, 5 mm Hg increase & $0.87(0.84-0.90)$ & $<0.001$ & $1.02(0.98-1.05)$ & 0.327 & $0.88(0.84-0.92)$ & $<0.001$ & $1.03(0.98-1.08)$ & 0.236 \\
\hline MAP, $5 \mathrm{~mm}$ Hg increase & $0.93(0.90-0.96)$ & $<0.001$ & $1.02(0.99-1.05)$ & 0.266 & $0.94(0.90-0.98)$ & 0.006 & $1.03(0.98-1.07)$ & 0.258 \\
\hline \multicolumn{9}{|l|}{$\mathrm{Na}<140 \mathrm{mmol} / \mathrm{L}(n=636)^{\mathrm{b}}$} \\
\hline $\mathrm{SBP}, 5 \mathrm{~mm} \mathrm{Hg}$ increase & $1.00(0.96-1.02)$ & 0.761 & $0.97(0.94-1.01)$ & 0.129 & $1.00(0.96-1.05)$ & 0.919 & $0.98(0.94-1.03)$ & 0.433 \\
\hline DBP, $5 \mathrm{~mm} \mathrm{Hg}$ increase & $0.85(0.81-0.89)$ & $<0.001$ & $0.99(0.93-1.04)$ & 0.650 & $0.84(0.78-0.90)$ & $<0.001$ & $0.98(0.91-1.06)$ & 0.646 \\
\hline MAP, $5 \mathrm{~mm}$ Hg increase & $0.90(0.86-0.94)$ & $<0.001$ & $0.98(0.93-1.03)$ & 0.315 & $0.90(0.84-0.96)$ & $<0.001$ & $0.98(0.91-1.05)$ & 0.512 \\
\hline \multicolumn{9}{|l|}{$\mathrm{Na} \geq 140 \mathrm{mmol} / \mathrm{L}(n=1,020)^{\mathrm{b}}$} \\
\hline $\mathrm{SBP}, 5 \mathrm{~mm} \mathrm{Hg}$ increase & $1.06(1.03-1.09)$ & $<0.001$ & $1.04(1.01-1.07)$ & 0.010 & $1.06(1.02-1.11)$ & 0.004 & $1.04(1.00-1.08)$ & 0.073 \\
\hline DBP, $5 \mathrm{~mm} \mathrm{Hg}$ increase & $0.89(0.86-0.93)$ & $<0.001$ & $1.03(0.99-1.08)$ & 0.167 & $0.93(0.87-0.99)$ & 0.021 & $1.07(1.00-1.14)$ & 0.058 \\
\hline MAP, $5 \mathrm{~mm} \mathrm{Hg}$ increase & $0.97(0.93-1.01)$ & 0.118 & 1.05 (1.003-1.09) & 0.034 & $0.99(0.94-1.06)$ & 0.850 & $1.06(1.02-1.13)$ & 0.043 \\
\hline
\end{tabular}

CI 1.08-1.54), 42.6 vs. 24.4 events per 1,000 patient-years (HR 1.36, 95\% CI 1.06-1.75), respectively\}. These data suggest that serum sodium concentration at baseline may predict outcomes in PD patients. We further performed a stratified analysis of serum sodium levels to evaluate the relationship between baseline SBP and mortality. Overall, continuous SBP levels were not associated with all-cause and CV mortality after adjusting for potential confounders (Table 3).

There was a significant interaction between baseline SBP and serum sodium for all-cause mortality ( $p$ for interaction $=0.016$ in the adjusted model), but not CV mortality ( $p$ for interaction $=0.203$ in the adjusted model). Table 3 shows HRs for mortality in the subgroup stratified by baseline serum sodium levels. With a 5-mm Hg elevation in SBP, adjusted HRs of all- 

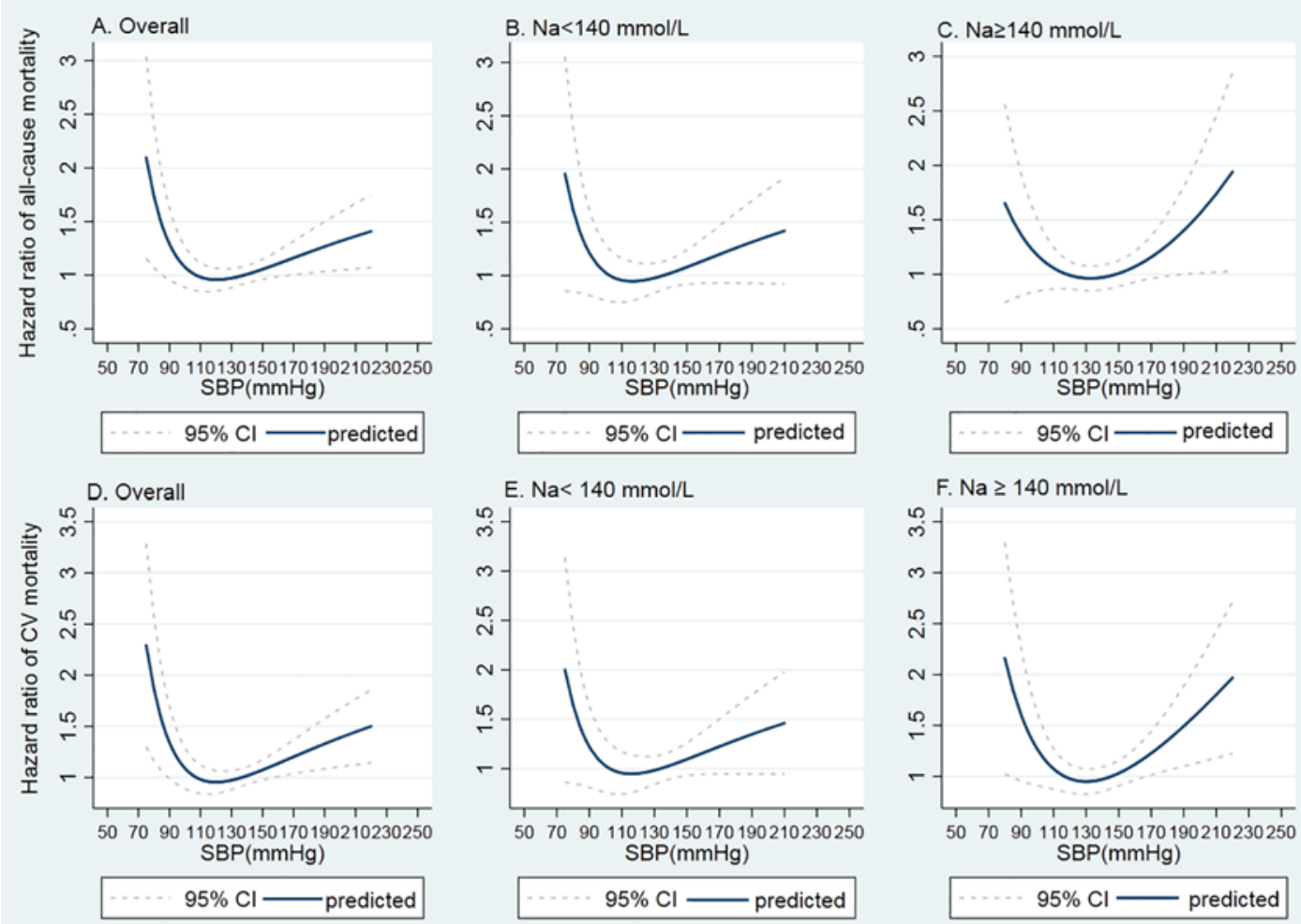

Fig. 1. The restricted cubic splines for baseline SBP with all-cause and CV mortality. SBP, systolic blood pressure; CV, cardiovascular; HR, hazard ratio.

cause and CV mortality were 1.04 (95\% CI 1.01-1.07, $p=0.010)$ and 1.04 (95\% CI 1.00-1.08, $p=0.073$ ), respectively, in participants with baseline serum sodium levels $\geq 140 \mathrm{mmol} / \mathrm{L}$. However, there was no significant association of SBP with all-cause or CV mortality in those with serum sodium levels $<140 \mathrm{mmol} / \mathrm{L}$.

Considering the nonlinear association between continuous SBP levels and outcomes, we conducted curve fitting with the HRs that were predicted from the Cox model. As shown in Figure 1, an approximate U-shaped association between SBP and risk of all-cause and CV mortality was observed. Patients with higher or lower SBP had higher risk of all-cause and CV mortality across serum sodium groups.

Based on these results, patients were split into 3 groups defined by SBP, with an SBP of 110-130 mm Hg as a reference. As shown in Table 4, in the entire cohort, all-cause mortality was greater in participants with SBP $<110$ or $>130 \mathrm{~mm} \mathrm{Hg}$, with adjusted HRs of 1.51 (95\% CI 1.12-2.03) and 1.40 (95\% CI 1.11-1.76), respectively. Similar results were observed for CV mortality, with adjusted HRs of 1.66 (95\% CI 1.09-2.53) and 1.50 (95\% CI 1.09-2.09) for participants with $\mathrm{SBP}<110$ or $>130 \mathrm{~mm} \mathrm{Hg}$, respectively. In the subgroup analysis, among participants with serum sodium $\geq 140 \mathrm{mmol} / \mathrm{L}, \mathrm{SBP}>130 \mathrm{~mm} \mathrm{Hg}$ was independently associated with increased all-cause mortality (HR: 1.45, 95\% CI 1.07-1.98, $p$ for interaction = 0.028 in the adjusted model), but not CV mortality (HR: 1.48, 95\% CI 0.94-2.31, $p$ for interaction $=0.257$ in the adjusted model). In participants with serum sodium levels $<140 \mathrm{mmol} / \mathrm{L}$, low SBP levels ( $<110 \mathrm{~mm} \mathrm{Hg}$ ), but not high SBP levels ( $>130 \mathrm{~mm} \mathrm{Hg}$ ) conferred an increased risk on both all-cause and CV mortality, with an adjusted HR of 1.99 (95\% CI 1.31-3.02) and 2.17 (95\% CI 1.17-3.96), respectively. 
Table 4. Association of baseline SBP groups with all-cause and CV mortality by baseline serum sodium levels

\begin{tabular}{|c|c|c|c|c|}
\hline & \multicolumn{2}{|l|}{ All-cause mortality } & \multicolumn{2}{|l|}{ CV mortality } \\
\hline & $\operatorname{HR}(95 \% \mathrm{CI})$ & $p$ value & $\operatorname{HR}(95 \% \mathrm{CI})$ & $p$ value \\
\hline \multicolumn{5}{|l|}{ Overall cohort $(n=1,656)^{\mathrm{a}}$} \\
\hline \multicolumn{5}{|l|}{ SBP groups } \\
\hline $110-130 \mathrm{~mm} \mathrm{Hg}$ & Ref & & Ref & \\
\hline$<110$ mm Hg & $1.51(1.12-2.03)$ & 0.007 & $1.66(1.09-2.53)$ & 0.019 \\
\hline$>130 \mathrm{~mm} \mathrm{Hg}$ & $1.40(1.11-1.76)$ & 0.004 & $1.50(1.09-2.09)$ & 0.015 \\
\hline \multicolumn{5}{|l|}{$\mathrm{Na}<140 \mathrm{mmol} / \mathrm{L}(n=636)^{\mathrm{b}}$} \\
\hline \multicolumn{5}{|l|}{ SBP groups } \\
\hline $110-130 \mathrm{~mm} \mathrm{Hg}$ & Ref & & Ref & \\
\hline$<110 \mathrm{~mm} \mathrm{Hg}$ & $1.99(1.31-3.02)$ & 0.001 & $2.17(1.19-3.96)$ & 0.011 \\
\hline$>130 \mathrm{~mm} \mathrm{Hg}$ & $1.27(0.89-1.82)$ & 0.184 & $1.55(0.94-2.57)$ & 0.087 \\
\hline \multicolumn{5}{|c|}{$\mathrm{Na} \geq 140 \mathrm{mmol} / \mathrm{L}(n=1,020)^{\mathrm{b}}$} \\
\hline \multicolumn{5}{|l|}{ SBP groups } \\
\hline $110-130 \mathrm{~mm} \mathrm{Hg}$ & Ref & & Ref & \\
\hline$<110 \mathrm{~mm} \mathrm{Hg}$ & $1.15(0.74-1.79)$ & 0.546 & $1.32(0.71-2.46)$ & 0.383 \\
\hline$>130 \mathrm{~mm} \mathrm{Hg}$ & $1.45(1.07-1.98)$ & 0.018 & $1.48(0.94-2.31)$ & 0.089 \\
\hline
\end{tabular}

SBP, systolic blood pressure; CV, cardiovascular; CVD, cardiovascular disease; CI, confidence interval. Bold values indicate $p$ values less than 0.05 . ${ }^{a}$ Multivariate models adjusted for age, gender, history of CVD, diabetic status, baseline serum sodium, hemoglobin, serum albumin, 24-h urinevolume, and anti-hypertension drugs. ${ }^{\mathrm{b}}$ Multivariate models adjusted for age, gender, history of CVD, diabetic status, hemoglobin, serum albumin, 24-h urine volume, and anti-hypertension drugs.

\section{Discussion}

In the present study, we demonstrated that participants with SBP $>130$ or $<110 \mathrm{~mm} \mathrm{Hg}$ had a significantly higher mortality risk compared with those with an SBP between 110 and $130 \mathrm{~mm} \mathrm{Hg}$. There was a significant interaction between baseline SBP and serum sodium for all-cause, but not CV mortality. Participants with serum sodium $<140 \mathrm{mmol} / \mathrm{L}$ were at greatest risk of all-cause and CV mortality when SBP was $<110 \mathrm{~mm} \mathrm{Hg}$. Conversely, those with serum sodium $\geq 140 \mathrm{mmol} / \mathrm{L}$ were at greatest risk when SBP was $>130 \mathrm{~mm} \mathrm{Hg}$. Our results suggest that serum sodium may alter the association of SBP with mortality. Put simply, both hypo- and hypertension are associated with worse outcomes in PD patients; but for those with lower serum sodium, the greatest risk is associated with hypotension, as opposed to those with higher serum sodium, for whom hypertension may carry the greater risk.

Previous large cohort studies have demonstrated that a higher serum sodium is associated with higher SBP in dialysis patients [15]. Although few reports have examined the associations between serum sodium and BP in PD patients, low-sodium dialysate lowers BP due to enhanced diffusive sodium removal $[16,17]$. More recently, Rutkowski et al. [13] performed a post hoc analysis of a prospective, randomized, controlled double-blind clinical trial comparing a sodium-reduced PD solution with a standard-sodium PD solution. They showed that for a glomerular filtration rate of $<6 \mathrm{~mL} / \mathrm{min} / 1.72 \mathrm{~m}^{2}$ on low-sodium dialysis fluid, SBP was reduced from $152 \mathrm{~mm} \mathrm{Hg}$ at baseline to $137 \mathrm{~mm} \mathrm{Hg}$ at week 12, and DBP decreased from 90 to $83 \mathrm{~mm} \mathrm{Hg}$ [13]. The beneficial effect is probably related to increased sodium clearance and reduced total body sodium. In the present study, our results showed that the serum sodium level was positively linearly associated with SBP levels among PD patients.

Many studies have attempted to investigate the impact of BP on clinical outcomes in both HD and PD patients [18-20]. For example, Zager et al. [18] found a U-shaped curve rela- 
tionship between post-dialysis SBP and the risk of CV mortality in HD patients. Results from a cohort of 24,525 incident HD patients demonstrated that patients with an SBP of 110-129 or SBP $\geq 160 \mathrm{~mm} \mathrm{Hg}$ had a higher mortality risk than those with an SBP of 130-159 mm Hg [20]. In the PD population, several studies have been reported that show a similar relationship between SBP and the risk of clinical outcomes, which indicates a greater risk for all-cause and CV mortality in patients with SBP $<110 \mathrm{~mm} \mathrm{Hg}$ or even $<120 \mathrm{~mm} \mathrm{Hg}$ [21, 22]. Similarly, our study also found a U-shaped relationship in PD patients, which showed that patients with baseline SBP $>130$ or $<110 \mathrm{~mm} \mathrm{Hg}$ had a significantly higher mortality risk than those with SBP between 110 and $130 \mathrm{~mm} \mathrm{Hg}$.

In subgroup analyses, we showed an interaction between baseline serum sodium concentration and BP for all-cause mortality. When the serum sodium level was $\geq 140 \mathrm{mmol} / \mathrm{L}, \mathrm{SBP}$ $>130 \mathrm{~mm} \mathrm{Hg}$ was associated with an increased risk of all-cause death. Conversely, when serum sodium levels were $<140 \mathrm{mmol} / \mathrm{L}$, patients with lower SBP $(<110 \mathrm{~mm} \mathrm{Hg})$ had an increased risk of all-cause and CV mortality. There may be different interpretations of such phenomena in PD patients. Recent studies have shown that sodium accumulation in the peritoneal interstitium leads to structural and functional changes in the peritoneum, while sodium accumulation in the interstitial skin was linked to left ventricular hypertrophy [23]. A metaanalysis by Borrelli et al. [24] showed that dialytic sodium removal was closely correlated with ultrafiltration in CAPD patients. Therefore, fluid overload produced by sodium accumulation and SBP > $130 \mathrm{~mm} \mathrm{Hg}$ may contribute to a multiplier interaction effect on the cardiac load and on the risk of CV mortality. Alternatively, hyponatremia is associated with a catabolic state and malnutrition in dialysis patients $[25,26]$. We suggest that malnutrition may contribute to the increased risk of mortality in patients with both serum sodium levels $<140$ $\mathrm{mmol} / \mathrm{L}$ and SBP $<110 \mathrm{~mm} \mathrm{Hg}$. However, in the present study, the association of SBP with outcomes remained significant after adjusting for BMI and serum albumin level, indicating that perhaps other physiological effects of lower serum sodium in PD patients could be in play. Based on our study results, further studies could consider whether individualized BP targets should take serum sodium into consideration, with treatment of hypertension perhaps being more important in those with higher serum sodium.

The major strength of this study is the relatively large study population and long followup period. In addition, to the best of our knowledge, the interaction between serum sodium and SBP has not been studied in CAPD patients. However, there were several limitations to this retrospective cohort study. First, it was a single-center study in Chinese CAPD patients, meaning that its generalizability may be limited. Second, we could not control for the impact of fluid status on BP or serum sodium because detailed information regarding the patients' body composition or fluid status was lacking. Similarly, a large number of patients in our study did not have baseline peritoneal equilibration test data. Therefore, we could not adjust for the impact of effects of membrane transport sodium and BP control. Third, the analysis was based on single serum sodium values and on office BP data rather than ambulatory-monitored BP data. Thus, we could not determine the impact of changes in these parameters on outcomes.

\section{Conclusion}

Our study showed that higher or lower SBP was associated with all-cause and CV mortality in our entire cohort. Association of BP with mortality was modified by serum sodium levels. Further studies are needed to verify whether individualized BP control that is based on a serum sodium level would contribute to improving PD patient outcomes. 


\section{Acknowledgements}

The authors thank all nephrologists and nurses in our PD center for their excellent management of PD patients. The authors also appreciate all nurses in our PD center for outcome data collection. We thank Jodi Smith, PhD, from Liwen Bianji, Edanz Editing China (www.liwenbianji.cn/ac), for editing the English text of a draft of this manuscript.

\section{Statement of Ethics}

This study was approved by the Ethics Committee of The First Affiliated Hospital of Sun Yat-sen University. Written informed consent was obtained from all participants.

\section{Conflict of Interest Statement}

All authors declare that they have no conflict of interest to disclose.

\section{Funding Sources}

This study was funded by Guangzhou Science and Technology Plan [201807010002]; National Key R\&D Program of China, Grant No. 2016YFC0906101; Operational Grant of Guangdong Provincial Key Laboratory, Grant No. 2017B030314019; and Key Laboratory of National Health Commission and Key Laboratory of Nephrology, Guangdong Province, Grant No. 2002B60118.

\section{Author Contributions}

All authors had access to the data and a role in writing this manuscript. H.P.M., Y.G.Q., and H.J.Y. contributed to the study conception and design. Y.G.Q. and H.J.Y. performed analyses of data, interpretation of data, and drafting manuscript. L.F., X.H.Z., and W.L. contributed to data collection and manuscript revision. H.P.M., X.F.H., W.C., and X.Y. provided overall supervision.

\section{References}

1 Ravel VA, Streja E, Mehrotra R, Sim JJ, Harley K, Ayus JC, et al. Serum sodium and mortality in a national peritoneal dialysis cohort. Nephrol Dial Transplant. 2017;32(7):1224-33.

2 Rhee CM, Ayus JC, Kalantar-Zadeh K. Hyponatremia in the dialysis population. Kidney Int Rep. 2019;4(6): 769-80.

3 Kovesdy CP, Lott EH, Lu JL, Malakauskas SM, Ma JZ, Molnar MZ, et al. Hyponatremia, hypernatremia, and mortality in patients with chronic kidney disease with and without congestive heart failure. Circulation. 2012; 125(5):677-84.

4 Rhee CM, Ravel VA, Ayus JC, Sim JJ, Streja E, Mehrotra R, et al. Pre-dialysis serum sodium and mortality in a national incident hemodialysis cohort. Nephrol Dial Transplant. 2016;31(6):992-1001.

5 Chang TI, Kim YL, Kim H, Ryu GW, Kang EW, Park JT, et al. Hyponatremia as a predictor of mortality in peritoneal dialysis patients. PLoS One. 2014;9(10):e111373.

6 Qiu Y, Ye H, Wang Y, Zhong Z, Li H, Huang F, et al. Age difference in the association between hyponatremia and infection-related mortality in peritoneal dialysis patients. Blood Purif. 2020:1-10.

7 Agarwal R, Flynn J, Pogue V, Rahman M, Reisin E, Weir MR. Assessment and management of hypertension in patients on dialysis. J Am Soc Nephrol. 2014;25(8):1630-46. 
8 Vaios V, Georgianos PI, Liakopoulos V, Agarwal R. Assessment and management of hypertension among patients on peritoneal dialysis. Clin J Am Soc Nephrol. 2019;14(2):297-305.

9 Banegas JR, Ruilope LM, de la Sierra A, Vinyoles E, Gorostidi M, de la Cruz JJ, et al. Relationship between clinic and ambulatory blood-pressure measurements and mortality. N Engl J Med. 2018;378(16):1509-20.

10 Herrett E, Gadd S, Jackson R, Bhaskaran K, Williamson E, van Staa T, et al. Eligibility and subsequent burden of cardiovascular disease of four strategies for blood pressure-lowering treatment: a retrospective cohort study. Lancet. 2019;394(10199):663-71.

11 Nakajima K, Oda E, Kanda E. The association of serum sodium and chloride levels with blood pressure and estimated glomerular filtration rate. Blood Press. 2016;25(1):51-7.

12 Rutkowski B, Tam P, van der Sande FM, Vychytil A, Schwenger V, Himmele R, et al. Low sodium balance study G: low-sodium versus standard-sodium peritoneal dialysis solution in hypertensive patients: a randomized controlled trial. Am J Kidney Dis. 2016;67:753-61.

13 Rutkowski B, Tam P, van der Sande FM, Vychytil A, Schwenger V, Klein G, et al. Residual renal function and effect of low-sodium solution on blood pressure in peritoneal dialysis patients. Perit Dial Int. 2019;39(4): 335-43.

14 Xu Q, Xiong L, Fan L, Xu F, Yang Y, Li H, et al. Association of pulmonary hypertension with mortality in incident peritoneal dialysis patients. Perit Dial Int. 2015;35(5):537-44.

15 Raimann JG, Canaud B, Etter M, Kooman JP, Levin NW, Marcelli D, et al. Association between pre hemodialysis serum sodium concentration and blood pressure: results from a retrospective analysis from the international monitoring dialysis outcomes (MONDO) initiative. J Hum Hypertens. 2016;30(7):442-8.

16 Nakayama M, Kawaguchi Y, Yokoyama K, Kubo H, Miura Y, Watanabe S, et al. Anti-hypertensive effect of low Na connection (120 mEq/L) solution for CAPD patients. Clin Nephrol. 1994;41(6):357-63.

17 Nakayama M, Yokoyama K, Kubo H, Matsumoto H, Hasegawa T, Shigematsu T, et al. The effect of ultra-low sodium dialysate in CAPD. A kinetic and clinical analysis. Clin Nephrol. 1996;45(3):188-93.

18 Zager PG, Nikolic J, Brown RH, Campbell MA, Hunt WC, Peterson D, et al. Dialysis clin I: "U" curve association of blood pressure and mortality in hemodialysis patients. Kidney Int. 1998;54:561-9.

19 Jhee JH, Park J, Kim H, Kee YK, Park JT, Han SH, et al. The optimal blood pressure target in different dialysis populations. Sci Rep. 2018;8(1):14123.

20 Robinson BM, Tong L, Zhang J, Wolfe RA, Goodkin DA, Greenwood RN, et al. Blood pressure levels and mortality risk among hemodialysis patients in the dialysis outcomes and practice patterns study. Kidney Int. 2012; 82(5):570-80.

21 Goldfarb-Rumyantzev AS, Baird BC, Leypoldt JK, Cheung AK. The association between BP and mortality in patients on chronic peritoneal dialysis. Nephrol Dial Transplant. 2005 Aug;20(8):1693-701.

22 Afshinnia F, Zaky ZS, Metireddy M, Segal JH. Reverse epidemiology of blood pressure in peritoneal dialysis associated with dynamic deterioration of left ventricular function. Perit Dial Int. 2016;36(2):154-62.

23 Borrelli S, De Nicola L, Minutolo R, Perna A, Provenzano M, Argentino G, et al. Sodium toxicity in peritoneal dialysis: mechanisms and "solutions". J Nephrol. 2020;33:59-68.

24 Borrelli S, La Milia V, De Nicola L, Cabiddu G, Russo R, Provenzano M, et al. Sodium removal by peritoneal dialysis: a systematic review and meta-analysis. J Nephrol. 2019;32(2):231-9.

25 Zevallos G, Oreopoulos DG, Halperin ML. Hyponatremia in patients undergoing CAPD: role of water gain and/ or malnutrition. Perit Dial Int. 2001;21(1):72-6.

26 Dekker MJ, Marcelli D, Canaud B, Konings CJ, Leunissen KM, Levin NW, et al. Unraveling the relationship between mortality, hyponatremia, inflammation and malnutrition in hemodialysis patients: results from the international MONDO initiative. Eur J Clin Nutr. 2016;70(7):779-84. 